\title{
O Fim do Programa de Aquisição de Alimentos: reviravoltas para mulheres extrativistas em Sergipe'

\author{
Heribert Schmitz ${ }^{2}$ \\ Dalva Maria da Mota ${ }^{3}$ \\ Glaucia Macedo Sousa ${ }^{4}$
}

\section{Resumo}

O objetivo do artigo é analisar a experiência de um grupo de mulheres extrativistas, catadoras de mangaba, após cinco anos de participação no Programa de Aquisição de Alimentos (PAA). A pesquisa foi realizada no povoado Pontal, Indiaroba, Sergipe, por meio de um estudo de caso com observações e entrevistas. As principais conclusões mostram que a execução do PAA: i) proporcionou a concretização de importantes demandas das catadoras de mangaba; ii) possibilitou a participação em um comércio justo; e iii) incentivou a mobilização delas e de parceiros fundamentais. O fim do PAA, entretanto, provocou: i) desmobilização por uma causa comum, a comercialização; ii) intensificação da diversidade de ocupações com maior precarização; e iii) maior diferenciação social.

Palavras-chave: Catadoras de mangaba. Programa de Aquisição de Alimentos. Políticas públicas. Comercialização.

\section{Introdução}

O tema do artigo é a influência do Programa de Aquisição de Alimentos $(\mathrm{PAA})^{5}$ na estruturação duradoura das práticas produtivas e de comercialização nos mercados locais de extrativistas de mangaba, autodesignadas "catado-

1 Pesquisa financiada com recursos do Conselho Nacional de Desenvolvimento Cientifico e Tecnológico (CNPq) do Ministério da Ciência e Tecnologia (MCT).

2 Doutor em Sociologia Rural, professor de Sociologia da Universidade Federal do Pará (UFPA), Belém/PA, bolsista de produtividade do CNPq. E-mail: heri@zedat.fu-berlin.de.

3 Doutora em Sociologia, pesquisadora da Embrapa Amazônia Oriental, Belém/PA, bolsista de produtividade do CNPq.E-mail:dalva.mota@embrapa.br.

4 Doutoranda no Programa de Pós-graduação em Sociologia e Antropologia (PPGSA) da UFPA, Belém/PA. E-mail: glauciarusso@ymail.com.

5 O Programa de Aquisição de Alimentos (PAA) foi criado pelo artigo 19 da Lei n. ${ }^{\circ}$ 10.696, de 2 de julho de 2003. 
ras de mangaba" (MOTA et al., 2011), que, depois de cinco anos, tiveram a participação no PAA interrompida.

O PAA foi constituído pelo Governo Federal em 2003 como uma das açóes estruturantes do Programa Fome Zero e tem como objetivo central "[...] garantir o acesso aos alimentos em quantidade, qualidade e regularidade necessárias às populaçóes em situação de insegurança alimentar e nutricional e promover a inclusáo social no campo por meio do fortalecimento da agricultura familiar" (BRASIL, 2012). Cumpre duas finalidades, as quais representam uma simbiose entre política agrícola e política social, "[...] com o mesmo recurso orçamentário" (DELGADO, 2013, p. 6). A primeira é garantir o acesso aos alimentos, a segunda é promover a produçáo rural com ênfase na comercialização dos produtos dos agricultores familiares, categoria de ação política constituída na década de 1990 e que pela lei inclui diferentes tipos de produtores familiares como agricultores, pescadores, silvicultores e extrativistas, dentre outros. Vários autores incluem as "compras públicas das diversas esferas de governo", a exemplo do citado programa, na perspectiva de um comércio justo e solidário (NUNES; SILVA, 2011; SCHMITT, C. J., 2011; SCHMITT, V. G. H., 2011).

Em mais de uma década de existência, pesquisadores como Chmielewska, Souza e Lourete (2010), Grisa et al. (2011) e Delgado (2013) estudam os diversos efeitos e mudanças que o programa causou nos processos produtivos (ampliação, valorização regional e resgate da diversificação da produção), na organização dos agricultores familiares (maior grau de organização em cooperativas e associaçóes) e na dieta alimentar da população beneficiada (quantidade e qualidade de alimentos). Além disso, indicam resultados inesperados como o resgate das culturas regionais, da autonomia e da autoestima de comunidades rurais.

Essas mudanças estão atreladas a um tipo de mercado institucional que, além de ser garantido, é lembrado por Grisa et al. (2011) como inovador por romper com tradicionais formas de comercialização que não levavam em consideração as especificidades dos agricultores familiares. Esse é o caso da lei de licitaçóes e contratos administrativos (Lei n ${ }^{\circ}$ 8. 666/93) e da Política de Garantia de Preços Mínimos (PGPM), caracterizados respectivamente pela complexidade e homogeneização de regras de mercado que, via de regra, impediram a participaçáo de agricultores familiares em mercados institucionais 
(compra de alimentos para escolas, hospitais e outras instituiçóes pelo poder público). Em oposição, a Lei n ${ }^{\circ} 10.696 / 2003$, que criou o PAA, autoriza a dispensa de licitaçáo na compra de produtos comercializados pelos agricultores familiares e as normas do programa levam em consideração que o preço dos alimentos ofertados deve estar relacionado a realidade e diferenças regionais.

Ao contrário de outras políticas como a Política do Seguro Desemprego ao Pescador Artesanal (PSDPA), o PAA não se constitui um direito dos beneficiários, mas tem o caráter de um programa que pode ser renovado ou interrompido, segundo critérios políticos e orçamentais. Por isso, Delgado (2013, p. 17) recomenda transformar o programa em uma política permanente de Estado.

Em que pese o reconhecimento às mudanças provocadas por um mercado inovador, o nosso objetivo, neste artigo, é analisar a experiência de um grupo de mulheres extrativistas, catadoras de mangaba, após o fim do PAA, programa a que tiveram acesso por cinco anos. A pergunta que orienta as nossas reflexóes é: o fim do PAA possibilitou a independência das catadoras em relação à inserção em mercados justos independentemente das políticas públicas, ou o grupo voltou a experimentar uma situação parecida com a que vivia antes de participar do programa?

Para tratar da questão, realizamos um estudo de caso no povoado Pontal, município de Indiaroba em Sergipe. Ali, reside um grupo de mulheres extrativistas, predominantemente negras e, na sua maioria, sem acesso à terra, cujo modo de vida é reconhecido como culturalmente diferenciado e abriga diferentes atividades, com destaque para o extrativismo vegetal (mangaba) e animal no mangue (caranguejo, aratu etc.). Para a pesquisa, apoiamo-nos também nos conhecimentos e experiências que acumulamos em mais de uma década de pesquisa sobre os diferentes aspectos do extrativismo da mangaba na regiáo, o que possibilita tratar da trajetória das catadoras antes, durante e depois do PAA. Para a fase atual da pesquisa, realizamos 22 entrevistas semiestruturadas ( $44 \%$ das mulheres que participaram no PAA), entrevistas informais e observaçóes das entregas, do recebimento da doação simultânea e do cotidiano das catadoras.

6 A questão inspirou-se nas reflexões de Chmielewska; Souza; Lourete (2010) em estudo realizado sobre o PAA em Sergipe. 
As 22 entrevistadas estão na faixa de 25 a 62 anos e têm aproximadamente 5 filhos ${ }^{7}$. Em vários casos, os filhos náo moram mais com elas, mas deixam alguns netos para elas cuidarem. A escolaridade é baixa, algumas têm a $4^{\mathrm{a}}$ série primária. Além da atividade como catadora de mangaba, 4 desenvolvem uma atividade comercial (bar, padaria, loja de material de construção, Cyber café simples), uma trabalha como diarista na casa de um citadino e uma recebe aposentadoria. A maioria (77\%) dos maridos trabalha como pescador. Três homens são também pedreiros, um faz "bico", dois coletam mangaba e coco, um recebe aposentadoria e um tem padaria e Cyber café.

Além da introdução e das consideraçóes finais, estruturamos o artigo em três partes que tratam da trajetória das catadoras no PAA. Na primeira parte, apresentamos o povoado Pontal como lugar de reproduçáo social de grupos camponeses alijados de processos de modernização da agricultura e, atualmente, reconhecidos como pertencentes ao segmento dos chamados povos e comunidades tradicionais ${ }^{8}$. Na segunda parte, analisamos os efeitos e as contribuiçóes do PAA para a concretização das principais demandas das catadoras de mangaba. $\mathrm{Na}$ terceira parte, analisamos como os efeitos do encerramento do PAA sáo interpretados, principalmente, na dinâmica do trabalho realizado pelas mulheres extrativistas.

\section{Pontal, onde vivem as catadoras de mangaba}

O povoado Pontal, localizado no litoral Sul sergipano (Mapa 1), chama a atençáo pela grande ocorrência de áreas de mangabeiras (Hancornia specios a Gomes) de uso comum com livre acesso e privado, pelas extensas áreas de manguezais que circundam toda a região e pela beleza do Rio Real, cuja travessia dá acesso a Mangue Seco, importante ponto turístico situado no Estado da Bahia. Com aproximadamente 250 famílias, calculamos que 60\% delas dependem do extrativismo vegetal e animal para sobreviver. No caso do primeiro, a atividade é exercida principalmente por mulheres que se autodenominam simultaneamente de catadoras de mangaba e de marisqueiras.

7 Todos os dados são de 2013.

8 Os povos e comunidades tradicionais são grupos sociais culturalmente diferenciados que se identificam como agentes do processo de desenvolvimento sustentável com baixo impacto sobre o meio ambiente e que são vistos dessa maneira pelo resto da sociedade. Esses povos são considerados como produtores de saberes e formas de manejo a eles pertinentes, essenciais na preservação da biodiversidade (ALMEIDA, 2000; CASTRO, 1997). 
Mapa I: Localização do povoado Pontal, município de Indiaroba (SE)
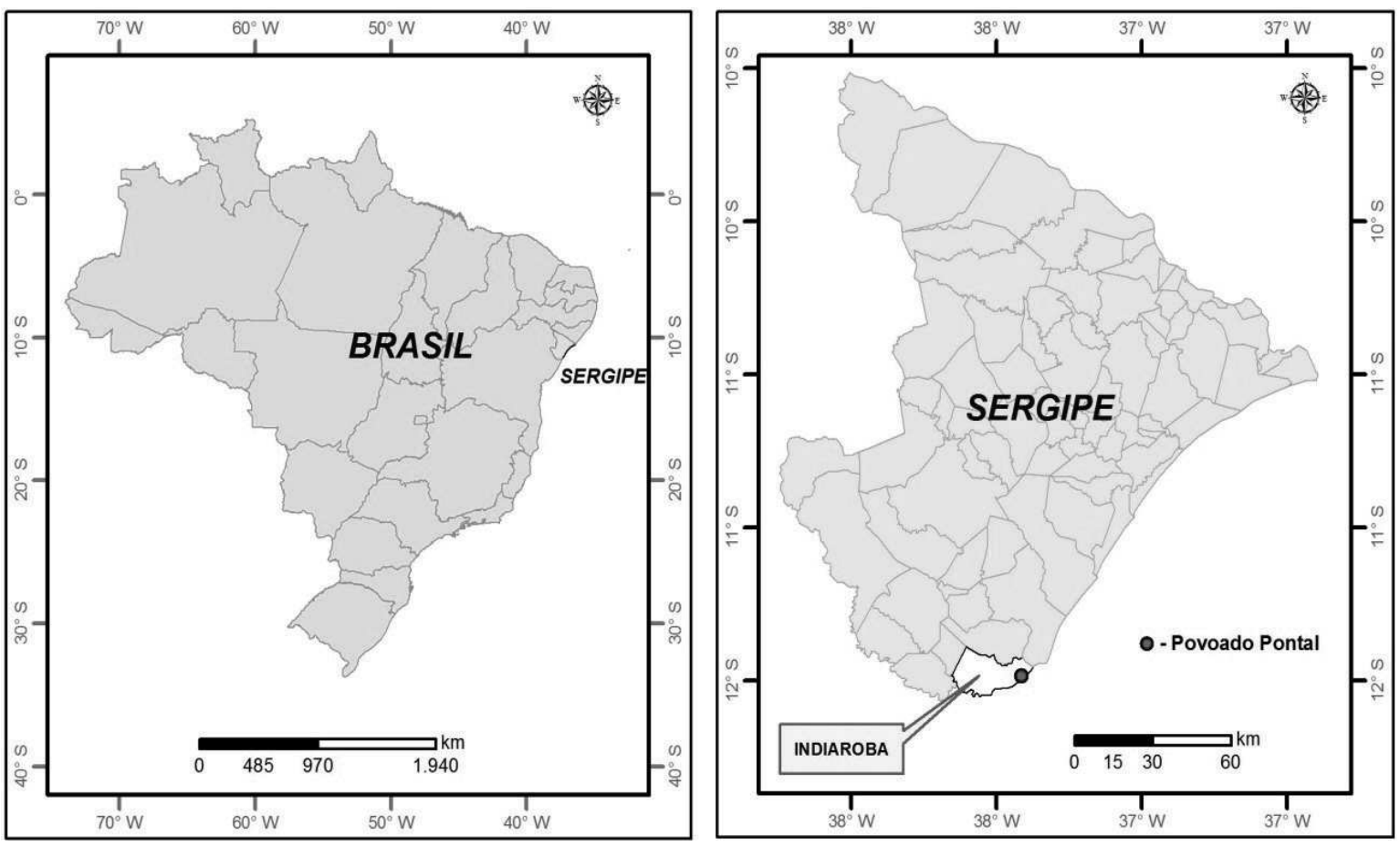

Fonte: Rocha (20/2).

A memória oral registra que, desde a formação do Pontal, diferentes geraçóes de mulheres realizam o extrativismo da mangaba em áreas privadas e de livre acesso. Nas primeiras, os proprietários, pertinentes às seis primeiras famílias que ocuparam o povoado, ao longo de noventa anos (ROCHA, 2012), permitiam a entrada das mulheres para coletar mangaba, tanto para o consumo, quanto para a venda direta (feiras, estradas e aos atravessadores). O livre acesso se dava, e persiste, em áreas devolutas (chamadas localmente de "terrenos de marinha") e em algumas parcas propriedades privadas.

Rocha (2012) também constatou que, entre as décadas de 1990 e 2010, o acesso às áreas privadas de mangabeiras começou a ser questionado por parte dos proprietários de terras no povoado Pontal. Esse grupo é formado não só pelos primeiros ocupantes, mas também por citadinos que construíram casas de veraneio e empresários interessados em investir na carcinicultura, agricultura, pecuária e construção de infraestruturas turística e imobiliária. Todas essas açóes demandam o corte das mangabeiras e, consequentemente, apontam para o questionamento do extrativismo da mangaba. A diferenciação social 
dos proprietários, muitos dos quais sem vínculos com os grupos nativos, implicam no redimensionamento de relaçóes anteriores que amparavam o acesso livre às plantas. As interdiçóes efetivam-se e, assim, em 58\% dos estabelecimentos, anteriormente acessadas pelas catadoras, o extrativismo foi proibido.

Durante muito tempo, o extrativismo da mangaba foi uma atividade de baixa remuneração" ${ }^{9}$ dada a falta de oportunidade de escoar os produtos em um comércio justo ${ }^{10}$, pois: "Antigamente eu vendia na feira, mas era tão barata a mangaba antigamente. Sacudia fora. Eram três litros, dois litros por um real, cinqüenta centavos de mangaba" (M. F. M., 46 anos) ${ }^{11}$. A expressão "sacudia fora" se refere ao ato da catadora preferir jogar fora as mangabas ao tê-las que vender a preços irrisórios, que mal pagavam os custos para chegar à feira. Essa ação das mulheres expressa uma primeira forma de protesto, a qual reclamava a falta de oportunidades em participar de um comércio justo. Trata-se de um protesto de caráter isolado e sem nenhuma organização, portanto, sem repercussóes na agenda de políticas públicas.

Como os produtos oriundos do extrativismo dependem dos períodos de safra, as mulheres extrativistas realizam diferentes atividades econômicas ao longo do ano, entre elas: o extrativismo animal, o trabalho assalariado ocasional relacionado ao mercado turístico (restaurantes, hotéis e pousadas de Mangue Seco) e vendas ambulantes de produtos aos turistas que chegam ao Pontal. Algumas mulheres trabalham temporariamente na colheita de coco em fazendas ou como diaristas e caseiras nas casas de praia.

Em reação à proibição da coleta da mangaba, estrutura-se uma proposta de demarcação de uma Reserva Extrativista (Resex Litoral Sul de Sergipe) na última década. No entanto, a demanda não foi acompanhada da formação de alianças e de ações duradouras que possibilitassem exercer uma pressão suficientemente forte junto ao poder público para viabilizá-la.

A reação das catadoras à morosidade da proposta de Resex e ao cercamento das áreas foi efetivada por um pequeno grupo de catadoras de mangaba ${ }^{12}$

9 Antes da participação no $P A A$, a renda familiar oriunda da venda da mangaba foi $26,6 \%$ do salário mínimo (dados de pesquisa de campo realizada em 2007; SCHMITZ; MOTA; SILVA JÚNIOR, 20II).

10 Também chamado de mercado justo.

11 Relato verbal durante a pesquisa de campo.

12 Considerando o cálculo de 2.500 mulheres catadoras de mangaba em Sergipe (MOTA et al., 20 II). 
(manifestação em atos públicos como na Marcha das Margaridas de 2011 e na Câmara dos Deputados e manifestaçóes na rua, em Aracaju, em 2014, dentre outras similaridades). As transgressóes clandestinas individuais foram intensificadas pela entrada das catadoras nas propriedades privadas com acesso interditado.

A esse comportamento das catadoras de mangaba, também quando se registra rumores ou boatos entre elas ou constata-se a prática de furtos, adequa-se bem a noção de resistência camponesa proposta nos trabalhos de James C. Scott que contribuem decisivamente "[...] para compreender este amplo leque de formas cotidianas, fragmentadas e difusas de resistência” (SCOTT, 2002, p. 10). O autor distingue entre formas de resistência pública declarada e formas de resistência disfarçada, discreta, oculta ou a infrapolítica, uma dimensão discreta da luta política. As formas discretas são mais comuns entre as extrativistas ${ }^{13}$. Essas formas desenvolvem-se em funçáo das diferentes práticas de dominação instauradas, distinguindo entre: dominação material, dominação de estatuto e dominação ideológica (SCOTT, 1990) ${ }^{14}$. Não visam a superaçáo da situação rejeitada em curto prazo e o resultado, no caso das mulheres extrativistas foi a continuidade de uma situação de pouca organizaçáo formal e a exclusão do acesso à terra e de políticas públicas para a grande maioria das catadoras de mangaba.

\section{O PAA no Pontal: cinco anos}

No ano de 2007, as catadoras de mangaba foram incentivadas a participar no PAA por meio da modalidade Compra com Doação Simultânea (CDS) ${ }^{15}$.

13 No caso dos camponeses, entre as diferentes formas de resistência disfarçada, o autor identifica: a caça clandestina, a ocupação de terras, as colheitas clandestinas, a adulteração das rendas em gêneros, boatos, rumores, criação de um espaço social autônomo para a formação da dignidade, religiōes populares, bandoleirismo social e de heróis populares (SCOTT, 1990).

14 A dominação material consiste na apropriação de um superior dos frutos de trabalho (produto, trabalho, taxas), a dominação de estatuto é atribuido em função do nascimento e usa práticas como a humilhação, o desfavorecimentos, os insultos, e a ataque à dignidade e, por último, a dominação ideológica impõe as justificativas pela situação de desigualdade estabelecida pela escravatura, a servidão, o sistema de castas ou os privilégios dos grupos dominantes (SCOTT, 1990, p. 198).

15 O Ministério do Desenvolvimento Social e Combate à Fome (MDS) repassa os recursos que estão sendo executados tanto por meio da Companhia Nacional de Abastecimento (CONAB), quanto por meio de estados e municípios. Nessa modalidade, os alimentos produzidos por agricultores familiares são comprados $e$ repassados para entidades integrantes da rede socioassistencial. O limite recebido por agricultor familiar foi $R \$ 4.500,00$ /ano. 
O arranjo institucional envolveu a Cooperativa de Produção, Comercialização e Prestação de Serviços dos Agricultores Familiares de Indiaroba e Região (COOPERAFIR), que possibilitou a participaçáo das catadoras no programa e a entrega das frutas para instituiçóes que atendem a populaçóes em situação de insegurança alimentar e nutricional na própria região ${ }^{16}$, e a Associação dos Moradores do Povoado Pontal e Periferia, que recebeu os produtos localmente.

O presidente da associação local - um agente de saúde - trabalhou voluntariamente com uma pequena equipe para garantir as condiçóes práticas da execução do programa, como viabilizar o local de distribuição (recepção de produtos oriundos de outras comunidades para os moradores do Pontal e entrega dos frutos oriundos do Pontal às associaçóes mencionadas anteriormente), disponibilizar uma balança para pesar os produtos, organizar a lista de controle de pagamento segundo a quantidade de produto e calcular o valor a ser recebido. Tudo isso em uma casa em construção mediante consentimento do seu proprietário e na sede da associação de moradores. Esta última foi utilizada também para a recepção dos produtos que foram ali mesmo separados para cada família e entregues a seus representantes.

Quanto à participação das catadoras, a formalização ocorreu por meio da Declaração de Aptidão ao Pronaf (DAP), emitido por organizaçóes como a Empresa de Desenvolvimento Agropecuário de Sergipe (Emdagro). Uma vez atendidos os requisitos, as mulheres participavam do programa com a entrega de mangabas, sendo que o Banco do Estado de Sergipe (BANESE) efetivava o pagamento delas por meio de um cartão bancário de uso individual, mas que, na prática, concentrava os recursos de mais de uma pessoa, pois aquelas que não conseguiram filiação formal contavam com o empréstimo do nome de uma amiga, parente ou vizinha para entregar as frutas e receber o dinheiro da venda. Esse rearranjo, com base em solidariedades primárias, promoveu o aumento do número de participantes no PAA, principalmente, daquelas que no início resistiram a participar, seja pela novidade em ter pagamento mensal, seja porque elas temiam perder recursos do PSDPA que várias catadoras de mangaba recebiam em função da sua condição de marisqueira. Além disso,

16 As doações foram destinadas às seguintes entidades: Associação de Moradores do Povoado Convento, Associação do Menor Aprendiz. Associação dos Produtores Rurais do Povoado Félix. Associação pela Cidadania dos Pescadores de Terra Caída e Associação Sergipana de Desenvolvimento Comunitário e Resgate da Cidadania (dados de 2010; pesquisa de campo). 
temiam romper relaçóes duradouras com os atravessadores pelo medo de que o PAA acabasse.

O acesso ao PAA por meio de associaçóes, parece ser o início da inserção das catadoras em uma rede de relaçóes que fortalecia antigas e formava novas alianças para a concretizaçáo de demandas latentes. No mesmo ano de integraçáo ao programa, em 2007, foi fundado o Movimento das Catadoras de Mangaba (MCM) como resultado do I Encontro das Catadoras de Mangaba de Sergipe. As principais reivindicaçóes das catadoras de mangaba nesse encontro podem ser resumidas em quatro temas: conservação dos recursos naturais e livre acesso às mangabeiras, inclusive com compra das áreas pelo governo; estímulo às catadoras que tem acesso à terra (sítio; assentamento) para plantar mais mangabeiras; participaçáo em todas as discussóes sobre a mangaba no Estado de Sergipe, especialmente sobre a comercialização e; criação de um "seguro-defeso da mangabeira" para o período da entressafra. A ideia da conservação das mangabeiras predominou no I Encontro: "Somos nós quem cuida das mangabeiras, das outras plantas e do mangue, por isso tem que conservar tudo" (MOTA; SCHMITZ; SILVA JÚNIOR, 2007, p. 29).

Para Schmitz et al. (2010, p. 174), com a criação do MCM, "[...] as catadoras de mangaba começaram a reagir e tornaram-se, pela primeira vez, atores visíveis nesse processo, passando da reaçáo escondida (transgressóes clandestinas) à iniciação de uma resistência organizada [...]”. Entre os anos de 2007 e 2009 registra-se uma série de açóes voltadas para a mobilização e formação das catadoras (I e II Encontro das Catadoras de Mangaba, ocorridos em 2007 e 2009 respectivamente) e a busca por apoio de instituiçóes nacionais, como a Comissáo Nacional de Desenvolvimento Sustentável dos Povos e Comunidades Tradicionais (CNPCT), bem como de instituiçóes do Estado de Sergipe. Além disso, denunciaram situaçóes que inviabilizavam a continuidade da atividade $^{17}$. Todas essas açóes, especialmente no estágio inicial da formação do MCM, contaram com o engajamento dos pesquisadores aliados que assessoram as catadoras desde 2003.

17 Uma das primeiras ações do MCM foi o envio de cartas enviadas ao Ministério Público Federal (MPF/SE), Ordem dos Advogados Brasileiros (OAB), o Ibama, a Administração Estadual de Meio Ambiente (Adema/SE), o Instituto Nacional de Colonização e Reforma Agrárias (Incra), o Ministério de Meio Ambiente (MMA) e a Secretaria Municipal de Ação Social Barra dos Coqueiros (SE). 
Posteriormente, as catadoras criaram ainda a Associação das Catadoras de Mangaba de Indiaroba (Ascamai), em Pontal, que contribuiu com a formalização da participaçáo delas num projeto para a produção de derivados da mangaba (doces, bombons, licor, etc.), financiado pela Petrobras, chamado localmente de "projeto dos doces" 18.

A experiência entre catadoras e instituições ligadas à execução e operacionalização do PAA no Pontal ocorreu entre os anos de 2007 e 2011. Nesses cinco anos, as catadoras experimentaram uma mudança significativa na sua qualidade de vida e nas estratégias de trabalho (MOTA et al., 2014).

As estratégias apontam para a substituição de antigas formas de acesso e coleta dos recursos. Foi registrada a presença dos homens em uma atividade considerada predominantemente feminina. Diferentemente da literatura sobre o papel das "mulheres da floresta" como seringueiras, castanheiras, pescadoras e curandeiras (SIMONIAN, 2001), no caso das catadoras de mangaba de Sergipe compete à mulher tornar possível o processo de trabalho com a "ajuda" de outros membros da família, assim como tomar decisóes relativas às atividades de pós-coleta e de comercialização. Assim, o PAA influenciou, também, na divisáo sexual do trabalho, porque, mediante o preço justo pago pelos frutos coletados no extrativismo, as mulheres foram valorizadas e os homens começaram se interessar pela atividade, como também analisado em outros contextos, a exemplo de estudo sobre a vida das rendeiras de Camalaú, no qual os homens começaram a fazer a renda renascença após a valorização econômica da atividade na Paraíba (ALBUQUERQUE; MENEZES; 2007).

Apesar das adversidades, a participaçáo no PAA foi lembrada como importante e compensadora, pois com o programa "A gente tinha um dinheirinho certo". A expressão utilizada pelas catadoras foi mencionada em diferentes contextos da pesquisa, no momento de execuçáo do PAA e, mais tarde, com o fim do mesmo quando indagadas sobre a principal contribuição do programa. A garantia de renda por meio do trabalho das mulheres teve seu efeito, principalmente, na superação da pobreza ${ }^{19}$, associada a: maior disponibilidade

18 Projeto Catadoras de Mangaba, Gerando Renda e Tecendo Vida em Sergipe (Edital público do Programa Petrobras Desenvolvimento E Cidadania, em parceria com a Universidade Federal de Sergipe e apoio do MCM.

19 Com Kageyama e Hoffmann (2006, p. 80), entendemos a pobreza aqui como uma “[...] privação, que pode ser somente material ou incluir elementos de ordem cultural e social, em face dos recursos disponiveis de uma pessoa ou familia. Essa privação pode ser de natureza absoluta, relativa ou subjetiva". 
de alimentos; menores jornadas de trabalho (menos autoexploração) e redução da pluriatividade, pagamento de contas; aquisição de bens de consumo e equipamentos para o trabalho; valorizaçáo econômica do fruto; a reduçáo da dependência dos atravessadores e; o incentivo a participaçáo das mulheres na arena pública, principalmente quando da atuação das mesmas no Movimento das Catadoras de Mangaba (MCM).

\section{I A experiência de um comércio justo}

Um dos aspectos que mais chama a atenção, é a menção ao preço justo para um produto costumeiramente desvalorizado e a atenção à legitimidade conferida ao mercado institucional. A este tema, em outro contexto e tempo, dedicou-se Edward Palmer Thompson, ao estudar os motins de subsistência na Inglaterra que tiveram frequentemente no seu cerne a questão da venda do pão a um preço justo, no século XVIII. O autor critica a visão redutora do homem econômico de muitos historiadores de desenvolvimento e mobiliza a noção de legitimidade que se encontra nas açóes da multidáo na época estudada. "Através do conceito de legitimaçáo, pretendo afirmar que os homens e as mulheres da multidão acreditavam estar a defender direitos ou costumes tradicionais e, em geral, ter o apoio de um amplo consenso comunitário" (THOMPSON, 2008, p. 22-23). Tinha "[...] um consenso popular acerca do que eram as práticas legítimas e as práticas ilegítimas de mercado [...] que, no seu conjunto, podem ser descritos como a economia moral dos pobres" (THOMPSON, 2008, p. 23).

A ideia da economia moral ganhou um lugar importante no conjunto de formas de resistência e estratégias de oposição ao sistema dominante, expressão que interpretamos persistente na reflexão sobre o PAA e sua contribuição para garantir a subsistência e reduzir o risco. Vários autores mostram a atualidade do uso do conceito da economia moral, como Woortmann (1990), no caso de camponeses brasileiros; Scott (1976), no estudo de camponeses na Malásia; e Lechat (2004), no campo da economia solidária. Nascimento (2013) discute a economia moral a partir de vários autores nos últimos anos e estabelece uma relaçáo com a obra de Scott (1976) que ampliou o conceito de Thompson, "[...] notadamente em termos de justiça social e reciprocidade" (NASCIMENTO, 2013, p. 13).

Ao recordar a execuçáo do PAA, as catadoras de mangaba referem-se constantemente às vantagens de participaçáo no programa, afirmando o seu 
sentimento de terem sido tratadas pela primeira vez de forma justa. Em relação às formas anteriores de negociação no processo de comercialização, elas destacam as diferenças que podiam ser sentidas no preço dos produtos, a exemplo de uma das entrevistadas, para a qual o PAA era mais vantajoso, porque o preço era "por quilo" e ainda tinha possibilidade de "entregar" outras frutas como o caju e a manga.

Para além dos consensos, em estudo realizado no povoado Pontal, Rocha (2012) observou que a venda regular de mangabas a preços justos para o PAA contribuíram para o aumento do conflito com os proprietários e entre as próprias catadoras que, com a escassez de áreas para coletar mangaba, passaram a disputar as frutas. Nesse cabo de guerra, buscavam diferentes estratégias, tais como: i) coletar somente dentro do povoado, o que exigia muitas vezes o envolvimento de toda a família - marido e filhos; ii) coletar para além das barreiras do povoado, tentando junto com amigos e parentes, que seguiam em pequenas embarcaçóes (canoas), alcançar as mangabeiras mais distantes, iii) comprar mangaba de proprietários de terras que reclamavam pela participação dos lucros no PAA; iv) coletar mangaba em uma fazenda e dividir o lucro com o proprietário, divisão essa que ocorria de forma desigual já que metade ficava para o dono da fazenda e a outra metade era dividida para o grupo composto por cerca de cinco ou seis catadoras que haviam trabalhado juntas.

A possibilidade de venda regular da mangaba levou à intensificação do extrativismo com o envolvimento náo usual de outros membros do grupo doméstico (companheiros, esposos) e, até mesmo, de grupos de parentes no processo de coleta e beneficiamento dos frutos. Com esse aumento da atividade extrativista e o cercamento simultâneo de áreas antes de livre acesso, foram registrados ocasionalmente práticas predatórias e uma diminuição do respeito às regras consuetudinárias, especialmente náo quebrar galhos e não catar frutas verdes (SCHMITZ; MOTA; SILVA JÚNIOR, 2009) ${ }^{20}$.

20 "Ao longo dos anos estabeleceram-se alguns consensos quanto ao que é considerado aceitável ou não no extrativismo da mangaba e que estão presentes nas memórias individual e coletiva [...]" (SCHMITZ; MOTA; SILVA JÚNIOR, 2009, p. 284). Essas regras consuetudinárias referem-se, principalmente, a: não quebrar galhos; não catar frutas verdes; e não cortar as mangabeiras. Foi observado que, nas áreas onde as catadoras de mangaba têm pleno acesso às árvores, os recursos naturais estão mais bem conservados do que onde prevalecem outras formas de acesso, como a compra das frutas (SILVA JúNIOR et al., 2006). 


\subsection{Por que acabou o PAA no Pontal?}

As mulheres participaram no PAA entre 2007 e 2011. O programa começou com a afiliaçáo de apenas seis mulheres. Contou com 30 mulheres registradas no momento da última "entrega", quando o programa foi interrompido em 2011.

Para a totalidade das mulheres entrevistadas, as razóes para essa medida não são claras. Contribui para a incerteza também a forma como circularam as informaçóes sobre as razóes da interrupção. Uma catadora de mangaba afirmou que as "entregas" acabaram, porque elas não têm mais onde praticar o extrativismo, porque os donos cercaram as propriedades e proibiram a coleta da mangaba depois que souberam que as catadoras estavam ganhando dinheiro. Ela reclamou ainda que nenhuma das lideranças explicou o porquê de ser finalizado o PAA no Pontal.

Argumento frequente foi o crescimento do tamanho do grupo com o consequente aumento do trabalho logístico para "entregar" os frutos e receber os demais produtos. Em 2011, o grupo contava com 50 participantes entre registradas e "afiliadas". Tornou-se difícil gerenciar o projeto com poucos voluntários náo remunerados em torno do presidente da associação que pesava, registrava e organizava o transporte dos produtos. A equipe voluntária teve que registrar também o volume entregue pelas mulheres não registradas "afiliadas". Tornava mais complexa a situaçáo, o fato das catadoras nunca terem participado de uma iniciativa formal de comercialização e terem inúmeras dúvidas quanto aos dias de entrega, volume a ser coletado, recursos a ser recebido, etc. A equipe era acionada amiúde para dar respostas que se intensificaram à proporção que os frutos rareavam.

A escassez dos frutos pelo aumento da demanda e pelo fechamento de áreas de livre acesso para as catadoras influenciou para que fosse mais difícil manter as regras consuetudinárias, especialmente pelas pessoas que não moravam no povoado, mas que tinham a possibilidade de, juntamente com alguma catadora registrada, participar da "entrega" no PAA. Várias estratégias foram postas em prática, como a mistura de frutos verdes e em vias de maturação, o que desagradou as instituiçôes receptoras. Ademais, ficou claro para uma das lideranças que os técnicos dessas últimas estavam insatisfeitos com o 
recebimento da mangaba pelo fato de ser uma fruta de delicado processamento, altamente perecível e que, por isso, exige cuidado rápido ${ }^{21}$.

Como em outras açôes coletivas, observa-se a tendência de aproveitar individualmente (OLSON, 1965) mediante a raridade de iniciativas dessa natureza, colocando a sobrevivência acima de qualquer objetivo. Aliás, em nenhuma das falas foi constatado que as pessoas estavam informadas quanto ao desfecho que esse tipo de evento poderia ocasionar, talvez por estarem envolvidas nas suas práticas de resistência individual (SCOTT, 2002), em um contexto severo de hostilidade à reprodução social.

Diferentemente das compreensões que circulam localmente, lideranças essenciais à execução do PAA informaram que os motivos do encerramento do PAA no Pontal foram o término do contrato com a Conab e a perspectiva de montagem de uma processadora de polpas. A iniciativa náo teve desdobramentos.

Qualquer que seja a explicação para o fim do PAA, constatamos que nem o MCM nem a Ascamai estiveram envolvidos na resolução de problemas relativos ao programa. Ao contrário da ação coletiva, entraram bastante em cena os boatos, rumores e os próprios atos individuais para garantir a sobrevivência. No entanto, nesses atos, não se trata de agressóes diretas contra os bens de colegas da categoria, o que excluiria essas práticas do enquadramento como "atos de resistência”, pois precisa-se de certo raciocínio para identificar as estratégias não cooperativas como prejudiciais aos interesses comuns (SCOTT, 2002).

Como o fim do PAA, prevaleceu a certeza de que o projeto seria retomado imediatamente. Quando ficou claro que o programa realmente acabou, estabeleceu-se certo clima de revolta que, no entanto, náo passou do discurso e do comportamento individual.

É importante registrar que, na raiz desses problemas, encontra-se, como constatado anteriormente em outros conflitos envolvendo o extrativismo da mangaba, a ação de atores externos que restringem o acesso aos recursos comuns, as mangabeiras (SCHMITZ et al., 2010).

21 Há um látex que gruda nas paredes dos processadores e liquidificadores e que exige atenção especial para a higienização. 


\section{O fim do PAA: "tudo volta a ser uma aventura"}

Na visão das catadoras, com o PAA havia a garantia da entrega das mangabas a um preço justo, o que permitia realizar investimentos com a certeza de que teriam como pagar. Com o fim do programa, conforme a fala de uma catadora, "tudo volta a ser uma aventura". Isto é, ocorre o retorno das incertezas e instabilidades decorrentes de um mercado frágil, onde o preço da mangaba é bastante variável e subjugado ao atravessador. Sendo assim, duas dimensóes são fortemente atingidas com as incertezas que voltam a pairar sobre o trabalho extrativista das mulheres: o acesso aos recursos e a comercialização das frutas.

\section{I Acesso aos recursos e comercialização das frutas}

Coincidência ou não, o fim do PAA marca o enfraquecimento da Associação dos Moradores do Povoado Pontal e Periferia. Simultaneamente, o MCM começa a perder força, apesar dos esforços empreendidos para a mobilizaçáo de diferentes órgãos públicos estaduais e nacionais, a ampla visibilidade alcançada nas mídias e a aprovação da proposta de uma lei estadual ${ }^{22}$ que reconhece as catadoras de mangaba como um grupo culturalmente diferenciado e estabelece o autorreconhecimento como critério do direito, em 2010. A partir do II Encontro das Catadoras de Mangaba de Sergipe, aumentou a discordância entre as catadoras em relação aos principais objetivos e estratégias como: acesso à terra tipo propriedade individual versus área de livre acesso; e extrativistas versus doceiras. Derrotas como a perda de perspectiva da criação de Unidade de Conservação (UC) $)^{23}$ para garantir o acesso às mangabeiras contribuíram para o enfraquecimento dessa mobilizaçáo. A sua conquista teria possibilitado o acesso das catadoras às áreas de mangabeiras, que começaram a ser cercadas pelos proprietários na última década.

Ao mesmo tempo, os donos de terra passaram a defender mais intensamente seus interesses e a propriedade da terra a partir de diferentes tipos de cerca que classificamos como: i) cerca material: cerca de arame farpado, sendo utilizada por antigos e recentes moradores, assim como também por catadoras

22 Lei $n^{\circ} 7.082$, de 16 de dezembro de 2010.

23 A área denominada Resex Litoral Sul de Sergipe, nos municipios de Indiaroba, Santa Luzia do Itanhy, Estância e Itaporanga d'Ajuda, está ainda em debate, mas enfrenta resistência em nível interministerial. 
que possuem sítios; ii) cerca humana: a partir da contratação de pessoas que reforçam a cerca material, impossibilitando ainda mais o acesso aos recursos, sendo uma estratégia de citadinos que não moram no povoado; e iii) cerca moral: a divulgação de juízo de valor que reforça uma imagem negativa das catadoras como "ladras" que quase sempre aparece acompanhada por ameaças ou promessas de punição de que a extrativista pode ser denunciada por roubo e enfrentar até violência física.

As catadoras enfrentam de diferentes maneiras as cercas e, a depender de como isso ocorre, o extrativismo é realizado com maior dificuldade. De um lado, existe um pequeno grupo de catadoras contratadas para realizar serviços domésticos e evitar a entrada de outras pessoas nos sítios de citadinos. Para estas, o trabalho extrativista ocorre com mais facilidade, já que, nesses espaços as mangabas são encontradas em maior quantidade e melhor qualidade. De outro lado, existem aquelas catadoras que acatam a proibição de coletar mangaba nas propriedades privadas e usam apenas as áreas de acesso livre, onde a escassez do recurso é visível.

Para as catadoras que coletam nas áreas privadas (proibidas), os problemas são intensificados. Elas são as maiores vítimas das difamaçóes que relacionam a imagem delas à de "ladras". As acusaçôes têm refletido na própria relação familiar, pois os maridos reclamam por ouvir piadinhas nos bares. Além disso, ocorre o fortalecimento de concorrência entre as catadoras, divididas entre as que preferem açóes individuais concretizadas numa corrida de quem chega primeiro nas áreas de acesso livre e algumas que, indiretamente, defendem a propriedade da terra, porque trabalham no fortalecimento das cercas com o objetivo de obter renda para a família.

Da mesma forma como o acesso aos recursos, a comercialização é marcada pela incerteza. Os preços variam de acordo com a safra e as exigências dos compradores. Em tempos de safra, o valor da caixa (aproximadamente 27 $\mathrm{kg}$ ) chega a custar entre R\$10 (valor mínimo) e R \$ 30 (valor máximo). Já em tempos de escassez da fruta (fora de safra), paga-se até $\mathrm{R} \$ 50$ pela caixa. Neste último caso, as catadoras que possuem acesso às áreas privadas têm mais chance de ganhar, enquanto as outras encontram poucas frutas nas áreas de livre acesso.

Os antigos compradores, os atravessadores, negociam um preço a ser pago depois da venda no mercado. Ocorre que os preços oscilam segundo o 
julgamento deles e o preço já negociado anteriormente diminui sob o argumento da deteriorização do produto. Muitas vezes, o pagamento também demora além do prazo combinado. Assim, as mulheres ficam impossibilitadas de planejar qualquer investimento, principalmente porque a quantia de dinheiro prevista poderá diminuir.

Outro comprador entra também em cena: as próprias catadoras de mangaba. A compra é realizada por meio de integrantes da Ascamai que participam do "projeto dos doces" e as exigências referem-se, sobretudo, à qualidade da fruta avaliada pelo aspecto físico. A vantagem neste caso é que o pagamento é realizado na hora da "entrega". No entanto, tanto as sócias da Ascamai quanto os atravessadores têm baixo poder de compra e nenhum dos dois grupos é capaz de levar uma quantidade significativa de mangaba. O volume é pouco quando comparado com a aquisição pelo PAA. As mulheres que participaram antes no programa passaram por um período de adaptação às novas condiçóes:

O ano passado mesmo, nós não tivemos mais a Conab e a gente não pode mais entregar. Ai, no ano passado, eu cheguei até a chorar, nem imaginava. A gente tirou muita mangaba, era na época de inverno, e quando a moça chegou, ela disse que não queria aquela quantidade. Eram oito caixas e ela só queria três. Ai, nós não tinha celular para perguntar. Ela dizia assim: tire a quantidade que tiver. E quando ela chegou, ela disse que não queria. Ai a gente foi chorar, né, a gente vai fazer o que com essas cinco caixas de mangaba se a gente não tem pra quem entregar? E na época da Conab não, a gente tinha certeza que quantos quilos tirasse, as caixas que a gente tirasse, a gente poderia entregar. Ai, agora a gente não tem a quem entregar, agora só tem prejuizo. (R. T. S., 35 anos) ${ }^{24}$.

Nesse processo de adaptação, as comparaçóes entre os diferentes contextos de comercialização da mangaba sáo inevitáveis (Quadro 1), especialmente considerando a intensificação do trabalho das mulheres, que tentam manter o padrão de conforto adquirido durante a execução do PAA.

Em um dos momentos de realizaçáo da pesquisa, que ocorreu no período fora de safra de mangaba, uma das entrevistadas trabalhava todos os dias no mangue e nos fins de semana ainda vendia cocadas em Mangue Seco, sendo todos os dias e horas preenchidos pelo trabalho, sem descanso.

24 Relato verbal durante a pesquisa de campo. 
Quadro I: Condições do extrativismo da mangaba em diferentes contextos

\begin{tabular}{|l|l|l|}
\hline & PAA: 2007 a 201 I & Pós PAA: 201 I até os dias atuais \\
\hline Acesso & $\begin{array}{l}\text { Mesmo com as cercas, } \\
\text { as mulheres não eram } \\
\text { intimidadas e coletavam os } \\
\text { frutos nas áreas abertas e } \\
\text { privadas. }\end{array}$ & $\begin{array}{l}\text { As catadoras são intimidadas a coletar nas áreas } \\
\text { privadas; algumas participam do processo de } \\
\text { interdição das áreas, agora com acesso restrito. }\end{array}$ \\
\hline Compradores & $\begin{array}{l}\text { Principal comprador era a } \\
\text { Conab. }\end{array}$ & $\begin{array}{l}\text { São, sobretudo, os atravessadores e as sócias da } \\
\text { Ascamai. }\end{array}$ \\
\hline Quantidade & $\begin{array}{l}\text { Os frutos eram entregues em } \\
\text { grande quantidade. }\end{array}$ & $\begin{array}{l}\text { Os frutos são entregues em pequenas } \\
\text { quantidades. }\end{array}$ \\
\hline Preços & $\begin{array}{l}\text { Variavam de acordo com o } \\
\text { mercado regional. }\end{array}$ & $\begin{array}{l}\text { Variam de acordo com a vontade do comprador, } \\
\text { que depende da qualidade da fruta e do lucro } \\
\text { obtido com a revenda. }\end{array}$ \\
\hline
\end{tabular}

Fonte: Pesquisa de campo.

\subsection{Para amenizar as incertezas}

Com a diminuição dos ganhos com o trabalho no extrativismo, a maioria das mulheres intensificou as ocupaçóes simultâneas para melhorar as possibilidades de renda e amenizar as incertezas. Assim, tentam garantir a quitaçáo de dívidas adquiridas e manter a sobrevivência dos filhos. Quando elas não estão no mangue e nas áreas de coleta de mangaba, estão em relaçóes de trabalho caracterizadas pela precariedade advinda de contrataçóes temporárias (para a colheita de coco em fazendas) e da informalidade (vendas ambulantes, trabalho como diaristas e caseiras nas casas de praia).

Para superar a desvalorizaçáo da força de trabalho, algumas catadoras abriram seus próprios negócios (lanchonete, estacionamento, padaria, venda de material de construção, mercearia e lan house). No entanto, como aquelas inseridas nas ocupaçóes mencionadas anteriormente, elas também precisam complementar a renda realizando mais de uma atividade. Isso mostra a fragilidade desse tipo de mercado de trabalho, que depende do poder de consumo dos moradores e do fluxo de turistas, principal público das vendedoras ambulantes e dos negócios.

Por fim, para amenizar as inseguranças existem aquelas que optaram por levar adiante a produção dos derivados da mangaba e que estáo organizadas 
por meio da Ascamai ${ }^{25}$. Embora os esforços empreendidos para o sucesso do empreendimento, fragilidades persistem também neste tipo de alternativa, as quais estáo relacionadas ao baixo rendimento das vendas e a impossibilidade de conciliaçáo das atividades do grupo com as tarefas de cuidado com as crianças, bem como a dificuldade de adaptação a novas habilidades ocupacionais.

Reforça a opção o fato de que uma parte das catadoras está interessada na criação de perspectivas para o futuro dos filhos.

Porque construindo dá para gerar emprego, a gente tem filho [...]. Eu tenho um filho já de maior [...] já tem catadoras ai mães que têm filhos que têm cursos. Vai ter muita coisa pra trabalhar, que vai gerar emprego. Eu sonho que vá adiante, que vá em frente e gere um movimento, que aqui é meio parado negócio de trabalho, serviço assim. Eu tenho esperança. Espero em Deus que vá adiante. (S., aproximadamente 40 anos). ${ }^{26}$

Em 2014, os produtos do grupo chegaram às escolas por meio do Programa Nacional de Alimentação Escolar (PNAE), mas sem continuidade.

Para uma catadora, o PAA, em comparação ao "projeto dos doces", era a melhor forma de participaçáo no mercado. Reforçando esse pensamento, outra catadora comparou os dois tipos de política pública e disse:

Porque a gente tinha uma renda certinha, né? Todo mês tinha um dinheirinho certinho [...]. Como eu falei, o projeto aí das meninas já tá com não sei quantas entregas - 3, 4, 5 entregas - e eles só pagam uma, duas. Ai, as meninas estão precisando do dinheiro. E dinheiro é muito pouco para dividir para 3, 4. Aí, uma recebe 70, outra 100, outra 150. Pra mim, não dá não. E não é todo mês certinho que eles pagam. (M.F. M., 46 anos). ${ }^{27}$

O financiamento desse projeto pela Petrobras terminou em 2015 e, portanto, as incertezas sáo sentidas cada vez mais nessa atividade que, por enquanto, conta com um estoque de material usado na fabricaçáo patrocinado pelo projeto.

O que chama atenção é o fato de que não somente as atividades econômicas são vistas como incertas. Da mesma maneira, as políticas públicas acessadas pelas catadoras são colocadas também no campo das "aventuras".

25 A Ascamai não tem apenas os integrantes do "projeto dos doces" entre seus associados.

26 Relato verbal durante a pesquisa de campo.

27 Relato verbal durante a pesquisa de campo. 
As mulheres argumentam que o Programa Bolsa Família dura até certa faixa etária dos filhos e não considera problemas familiares que podem impedir o atendimento das exigências de tal política ${ }^{28}$. O mesmo sentimento estende-se ao PSDPA, pela dificuldade de afiliação e atrasos do recurso.

O que chama atençáo é o argumento de que, diferente do que ocorria no PAA, nessas políticas elas não podem cobrar o dinheiro atrasado, porque esse náo é fruto do trabalho delas. Isso mostra que além de insegurança, o fim do projeto deixou marcas na autoestima das mulheres, orgulhosas de ter os ganhos obtidos a partir do fruto do trabalho realizado tradicionalmente por elas: "Eu tinha porque eu sabia [...] é meu. Eu entreguei. Eu tinha certeza que eu ia receber, porque eu tive o que entregar, né?" (R. T. S., 35 anos) ${ }^{29}$.

\section{Considerações finais}

O nosso objetivo foi compreender a experiência de um grupo de mulheres extrativistas, autodenominadas catadoras de mangaba, que habitam no povoado Pontal, município de Indiaroba (SE), e cuja participaçáo no PAA foi interrompida depois de cinco anos de funcionamento do programa localmente.

Os principais resultados mostram que a execução do PAA proporcionou a concretização de importantes demandas das catadoras de mangaba em relação à qualidade de vida (reforma de casas, aquisiçáo de alimentos, eletrodomésticos e equipamentos de trabalho, quitaçáo de contas, etc.). Proporcionou, ainda, a facilidade de acesso a outras políticas públicas pela possibilidade de regularização de documentos pessoais e de deslocamentos a sedes municipais para o atendimento à burocracia das mesmas (Bolsa Família e PSDPA).

Em se tratando das relaçóes entre as catadoras e as instituições, concluímos que, por um lado, o PAA incentivou o apoio ocasional de aliados importantes para o funcionamento do programa localmente. Por outro, facilitou o acesso a informaçóes quanto a outras possibilidades de comercialização, a exemplo do PNAE que foi, posteriormente, acessado por um pequeno grupo de catadoras, mas sem continuidade.

28 Foi o que nos fez refletir uma das entrevistadas, cujo filho de 14 anos estava dependente de drogas e já não frequentava a escola. Nesse caso: "consta que falta, né? Aí, eu posso passar o cartão qualquer dia e não vim, porque eu já passei sem receber por causa disso" (R. T. S., 35 anos; Relato verbal durante a pesquisa de campo). 
O encerramento do PAA no povoado Pontal foi um caso particular, ligado à operacionalização do programa localmente e às características de perecibilidade da fruta (mangaba).

Desde a finalizaçáo do PAA, as catadoras dependem dos tradicionais canais de comercializaçáo cujos atores também enfrentam vulnerabilidades e têm pouco poder de compra. Ademais, mediante a diminuição do acesso aos recursos crescentemente devastados e cercados as catadoras dependem crescentemente da pluriatividade e de mercados de trabalho, cujas relaçóes são precárias. Intensificam assim, a participação em atividades que corroboram para a ampliação das incertezas.

De maneira atomizada, algumas mulheres foram incentivadas a pensar alternativas econômicas, ter os seus pequenos negócios e a participar individual ou coletivamente de iniciativas de geraçáo de renda. Entretanto, elas náo superam 15\% das catadoras que participaram do PAA. Mesmo assim, reforçam o indicativo de diferenciação social.

Reflexão à parte merece a questão do comércio justo. Nesse âmbito, concluímos que a participaçáo no PAA representou um marcante acontecimento, pois, pela primeira vez, as mulheres participaram de uma iniciativa que valorizava o fruto do seu trabalho e a sua própria condição de catadora e os seus reflexos na autoestima persistem.

Quanto à pergunta que levantamos neste artigo, concluímos que as catadoras voltaram a experimentar uma situaçáo parecida com a que viviam antes de participar do programa, porque houve uma tendência à prática da resistência individual e cotidiana em detrimento da açáo coletiva organizada, como mostra a pouca importância das suas organizações nos momentos de crise e para a resolução de conflitos.

Nenhuma mobilização com fins de reivindicar o retorno da participação no PAA foi constatada, embora a perda do acesso ao programa e à garantia do pagamento de um preço justo tenha sido muito dolorosa para as catadoras de mangaba.

\section{Referências}

ALBUQUERQUE, E. de F; MENEZES, M. O valor material e simbólico da renda renascença. Estudos Feministas, Florianópolis, v. 15, n. 2, p. 461-467, maio-ago. 2007. 
ALMEIDA, M. Entrevista do mês - As reservas extrativistas e as populações tradicionais. Com Ciência, n. 15, nov. 2000. Disponível em: <http://www.comciencia.br/entrevistas/almeida. htm>. Acesso em: 7 mar. 2016.

BRASIL. Ministério do Desenvolvimento Social e Combate à Fome. Programa de Aquisiçáo de Alimentos: renda para quem produz e comida na mesa de quem precisa. Brasília: Ministério do Desenvolvimento Social e Combate à Fome, 2012. Disponível em: <http:// www.mda.gov.br/sitemda/sites/sitemda/files/user_arquivos_64/CARTILHA_PAA_FINAL. pdf>. Acesso em: 7 mar. 2016.

CASTRO, E. Território, biodiversidade e saberes de populaçóes tradicionais. In: CASTRO, E.; PINTON, F. (Org.). Faces do trópico úmido: conceitos e questóes sobre desenvolvimento e meio-ambiente. Belém, PA: Cejup, 1997. p. 263-283.

CHMIELEWSKA, D.; SOUZA, D.; LOURETE, A. A. O Programa de Aquisiçáo de Alimentos da Agricultura Familiar (PAA) e as Práticas dos Agricultores Participantes Orientadas ao Mercado: estudo de caso no Estado de Sergipe. Brasília: IPEA, 2010. (Texto para Discussão n. 1510).

DELGADO, G. C. Pesquisa de avaliação de concepçáo e implementaçáo do Programa Aquisição de Alimentos - PAA: relatório de avaliação do PAA (Síntese). Brasília: Conab; PNUD, 2013. 17 p. Mimeografado.

GRISA, C.; SCHMITT, C. J.; MATTEI, L. F.; MALUF, R. S.; LEITE, S. P. Contribuiçôes do Programa de Aquisição de Alimentos à segurança alimentar e nutricional e à criaçáo de mercados para a agricultura familiar. Agriculturas, Rio de Janeiro, v. 8, n. 3, p. 34-41, set. 2011.

KAGEYAMA, A.; HOFFMANN, R. Pobreza no Brasil: uma perspectiva multidimensional. Economia e Sociedade, Campinas, v. 15, n. 1, p. 79-112, jan./jun. 2006.

LECHAT, N. M. P. Trajetórias intelectuais e o campo da economia solidária no Brasil. Tese (Doutorado em Ciências Sociais) - Programa de Pós-Graduação em Ciências Sociais, Universidade Estadual de Campinas, Campinas, 2004.

MOTA, D. M. da; SCHMITZ, H.; SILVA JÚNIOR, A. da. (Des)acordos quanto ao uso dos recursos naturais em contexto de transformaçáo fundiária em Sergipe. Ambiente \& Sociedade, São Paulo, v. 18, n. 2, p. 43-60, abr.-jun. 2015. (Dossiê Direito, Meio Ambiente e Território). .; ___ _ _ SILVA JUNIOR, J. F. da. Relatório do I Encontro das Catadoras de Mangaba. Aracaju: Embrapa Amazônia Oriental/Embrapa Tabuleiros Costeiros/Universidade Federal do Pará, 2007. 
.; .; .; PORRO, N. M.; OLIVEIRA, T. C. V. de. As catadoras de mangaba no Programa de Aquisição de Alimentos - PAA: um estudo de caso em Sergipe. Revista de Economia e Sociologia Rural, Piracicaba-SP, v. 52, n. 3, p. 241-262, jul/set 2014. .; SILVA JÚNIOR, J. F. da; SCHMITZ, H.; BRITO, J. V. S. As senhoras da mangaba. In: MOTA, D. M. da; SILVA JÚNIOR, J. F. da; SCHMITZ, H.; RODRIGUES, R. F. A. (Ed.). A mangabeira, as catadoras, o extrativismo. Belém: Embrapa Amazônia Oriental; Aracaju: Embrapa Tabuleiros Costeiros, 2011. p. 105-137.

NASCIMENTO, C. G. do. Trajetórias de um conceito: a economia moral dos pobres. Revista Raízes, Campina Grande, v. 33, n. 2, p. 10-28, 179, jul.-dez. 2013.

NUNES, C. G. F.; SILVA, P. H. I. Rumo a um novo mercado: uma abordagem sociológica do comércio justo e solidário. Mercado de Trabalho, Brasília, n. 49, p. 67-76, nov. 2011.

OLSON, M. The logic of collective action: public goods and the theory of groups. Cambridge, MA: Harvard University Press, 1965.

ROCHA, M. M. L. Conflitos sociais pelo acesso aos recursos: o extrativismo da mangaba (Hancornia speciosa Gomes) no Povoado Pontal/Sergipe. Dissertação (Mestrado em Agriculturas Familiares e Desenvolvimento Sustentável) - Programa de Pós-Graduação em Agriculturas Amazônicas, Universidade Federal do Pará; Embrapa Amazônia Oriental, Belém, 2012.

SCHMITT, C. J. Encurtando o caminho entre produção e o consumo de alimentos. Agriculturas, Rio de Janeiro, v. 8, n. 3, p. 4-8, set. 2011.

SCHMITT, V. G. H. As dimensóes da sustentabilidade nas relaçóes de poder. Tese (Doutorado em Administração) - Fundação Getúlio Vargas, Escola Brasileira de Administração Pública e de Empresas, Rio de Janeiro, 2011.

SCHMITZ, H.; MOTA, D. M. da; SILVA JÚNIOR, J. F. da. Gestão coletiva de bens comuns no extrativismo da mangaba no Nordeste do Brasil. Ambiente \& Sociedade, São Paulo, v. 12, n. 2, p. 273-293, jul./dez. 2009.

.; ___ __ _ _ JESUS, N. B. de. Conflitos Sociais em Debate: O Caso das Catadoras de Mangaba no Nordeste e Norte do Brasil. Revista Estudos de Sociologia, Recife, v. 16, n.1, p. 157-178, jan.-jun. 2010.

.; ___ __ Mangabeiras cercadas e soltas: formas de acesso, coleta e gestão das plantas. In: MOTA, D. M. da; SILVA JÚNIOR, J. F. da; SCHMITZ, H.; RODRIGUES, R. F. A. (Ed.). A mangabeira, as catadoras, o extrativismo. Belém: Embrapa Amazônia Oriental; Aracaju: Embrapa Tabuleiros Costeiros, 2011. p. 171-202. 
SCOTT, J. C. Domination and the Arts of resistance: hidden transcripts. New Haven; London: Yale University Press, 1990.

SCOTT, J. C. Formas cotidianas da resistência camponesa. Revista Raízes, Campina Grande, v. 21, n. 1, p. 10-31, jan.-jun. 2002.

SCOTT, J. C. The moral economy of the peasant: rebellion and subsistence in southeast Asia. New Haven; London: Yale University Press, 1976.

SILVA JÚNIOR, J. F. da; ARAÚJO, I. A.; BARREIRO NETO, M.; ESPÍNDOLA, A. C. M.; CARVALHO, N. S. G.; MOTA, D.M. da. Recursos genéticos nos tabuleiros costeiros e baixada litorânea do Nordeste. In: SILVA JÚNIOR, J. F. da; LÉDO, A. S. (Ed.). A cultura da mangaba. Aracaju: Embrapa Tabuleiros Costeiros, 2006. p. 57-74.

SIMONIAN, L. T. L. Mulheres da floresta amazônica: entre o trabalho e a cultura. Belém: UFPA: NAEA, 2001.

THOMPSON, E. P. A economia moral da multidáo na Inglaterra do século XVIII. Tradução F. Ágoas; J. Neves. Lisboa: Antígona, 2008. Original: Past \& Present, 1971.

WOORTMANN, K. "Com parente não se neguceia": o campesinato como ordem moral. In: Anuário Antropológico/87. Brasília: Editora Universidade de Brasília, Tempo Brasileiro, 1990. p. 11-73.

Recebido em: 19/05/2016.

Aceito em: 09/12/2016.

\section{The End of the Food Acquisition Program: turnarounds for gatherer women in the State of Sergipe, Brazil}

\section{Abstract}

The objective of this article is to analyze the experience of a group of mangaba gatherer women, after five years participating in the Food Acquisition Program (PAA). The research was realized in the village Pontal, Indiaroba, Sergipe, through a case study with observations and interviews. The main findings show that the implementation of the PAA: i) provided the achievement of important demands of the mangaba gatherer women; ii) made possible the participation in a fair trade; and iii) encouraged their mobilization together with key partners. The end of the PAA, however, caused: i) demobilization for a common cause, the comercialization; ii) enhancement of the diversity of occupations with more precarious work; and iii) greater social differentiation.

Keywords: Mangaba gatherer women. Food Acquisition Program. Public policy. Comercialization. 